\title{
Cucurbit[7]uril as a Supramolecular Artificial Enzyme for Diels-Alder Reactions
}

\author{
Aniello Palma, Markus Artelsmair, Guanglu Wu, Xiaoyong Lu, Steven J. Barrow, Najib Uddin, \\ Edina Rosta, Eric Masson* and Oren A. Scherman**
}

\begin{abstract}
The ability to mimic the activity of natural enzymes using supramolecular constructs (artificial enzymes) represents a vibrant scientific research field. Herein, we demonstrate that cucurbit[7]uril (CB[7]) can catalyze Diels-Alder reactions for a number of substituted and unreactive $\mathrm{N}$-allyl-2-furfurylamines under biomimetic conditions, without the need for protecting groups, yielding powerful synthons in previously unreported mild conditions. $C B$ [7] rearranges the substrate in a highly reactive conformation and shields it from the aqueous environment, thereby mimicking the mode of action of a natural Diels-Alderase. These findings can be directly applied to the phenomenon of product inhibition observed in natural Diels-Alderase enzymes, and pave the way toward the development of novel, supramolecular-based green catalysts.
\end{abstract}

In 2015, Fage and co-workers showed through specific mutations that the sole role of the enzyme SpnF, is to catalyze a [4+2] cycloaddition in the biosynthesis of spinosyn insecticides. ${ }^{[1]}$ Previously, the existence of Diels-Alderase

\footnotetext{
** OAS and AP acknowledge an ERC starting investigator grant (ASPiRe 240629) and EPSRC Programme Grant (NOtCH, EP/L027151/1) for the support, GW thanks the Leverhulme Trust (Natural material innovation for sustainable living) for the support, SJB thanks the European Commission for a Marie Curie Fellowship (NANOSPHERE, 658360), ER gratefully acknowledges financial support from EPSRC (EP/N020669/1), EM and XL acknowledge the American Chemical Society Petroleum Research Fund (PRF No. 51053-ND4), the Department of Chemistry and Biochemistry, the College of Arts and Sciences and the Vice President for Research at Ohio University. Additional data related to this publication is available at the University of Cambridge data repository (https://doi.org/10.17863/CAM.12345)
}

* Dr A. Palma, Mr M. Artelsmair, Dr G. Wu, Dr S. J. Barrow and Prof O. A. Scherman

Melville Laboratory for Polymer Synthesis

Department of Chemistry, University of Cambridge

Lensfield Road, Cambridge, CB2 1EW, UK

E-mail: oas23@cam.ac.uk

Dr X. Lu and Prof. E. Masson

Department of Chemistry and Biochemistry

Ohio University

Athens, Ohio 45701, USA

E-mail: masson@ohio.edu

Mr N. Uddin and Dr E. Rosta

Department of Chemistry

King's College London, London SE1 1DB, UK

Supporting information for this article is available on the WWW under or from the author. enzymes had remained elusive as structural similarity between starting material and product was thought to lead to full product inhibition of the active site. ${ }^{[2,3]}$ The catalytic abilities of these enzymes have been associated with their capacity to remove water molecules surrounding the substrate, stabilize its reactive geometry and enhance the reactivity of the dienophile. ${ }^{[1]}$ Inspired by nature, chemists have attempted to mimic enzyme reactive sites through the hostguest chemistry of bowl-shaped macrocyclic structures. ${ }^{[4-10]}$ One class of macrocyclic host molecules, cucurbit $[n]$ urils ( $\mathrm{CB}[n]$, where $n=5-8)$, have been utilized in the catalysis of oxidation, solvolysis, photochemical and metal-ion assisted reactions. ${ }^{[11-20]}$

$\mathrm{CB}[n]$ s consist of $n$ glycoluril units (where $n$ is typically between 5 and 8 ) that are bound via methylene bridges in a ring-like arrangement (Figure 1a). ${ }^{[1]}$ The number of repeat units defines the portal size and cavity volume. The dipolar nature of the carbonyl-fringed portals of $\mathrm{CB}[n] \mathrm{im}-$ parts a high cation binding affinity arising from an iondipole effect, whereas the inner cavity of $\mathrm{CB}[n]$ is remarkably hydrophobic. As this class of macrocycle can shield organic molecules from aqueous environments while encapsulating them in a hydrophobic cavity and promote cycloaddition reactions, ${ }^{[22-24]}$ cucurbit[ $\left.n\right]$ uril macrocycles, $\mathrm{CB}$ [7] inparticular due to its high water solubility, are ideal candidates to imitate the function of a Diels-Alderase enzyme active site. ${ }^{[1,20,21]}$

Cycloaddition products of $N$-allyl-2-furfurylamine derivates 1a-d (Figure 1b) can be subsequently manipulated with high selectivity leading to powerful synthons as well as various target molecules. ${ }^{[25-33]}$ However, these derivatives do not undergo cycloaddition in an efficient manner without the use of activating or bulky protecting groups on the secondary amine, which aid in bringing the diene and the dienophile in close proximity in-order to react. ${ }^{[31,34,35]}$

Herein, we demonstrate that $\mathrm{CB}$ [7] promotes intramolecular [4+2] cycloaddition reactions, in biomimetic conditions, of unactivated and unprotected $N$-allyl-2-furfurylamine derivatives (Figure 1). Compounds 1a-d (Figure 1b) will establish an interaction between the protonated secondary amine and the carbonyl portal of $\mathrm{CB}$ [7], promoting the encapsulation of the hydrophobic residues (furan and propene) within the cavity of the macrocycle. This in turn leads to a hair-pin induced conformation of the substrate within $\mathrm{CB}$ [7] (Figure 1c, CB[7]-HIC). In this arrangement, the diene and the tethered dienophile are in a favorable orientation 
(a)

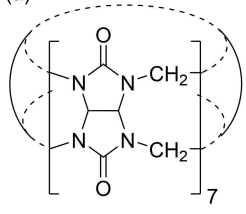

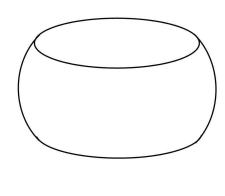

(b)

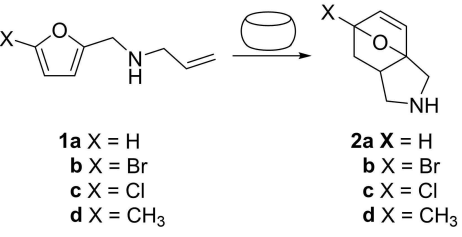

(c)

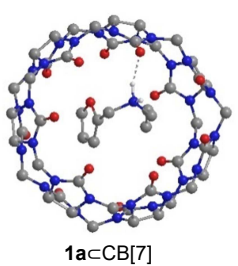

(d)

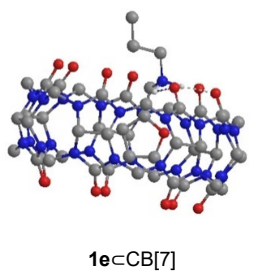

Figure 1. Cucurbit[7]uril as a Diels-Alderase. a) Structure of CB[7]. b) The structure of the substrates developed for the CB[7]-Diels-Alderase catalysis along with the product of the catalyzed reaction. c) Lowest energy minimized geometry of the 1a substrate within the CB[7] cavity, at a hair-pin induced conformation (HIC). d) Energy minimized structure of $1 \mathrm{e} \subset \mathrm{CB}[7]\left(-\mathrm{NHCH}_{2} \mathrm{CH}_{2} \mathrm{CH}_{3}\right)$.

to undergo a [4+2] cycloaddition (see Table 1 and ESI Figures $\mathrm{S} 12$ and $\mathrm{S} 14)$.

With the aim to investigate the stoichiometry and conformation of the CB[7]-HIC complex, NMR studies and ITC experiments were performed. An ITC titration of 1a into a solution of $\mathrm{CB}$ [7] showed the formation of a 1:1 complex with a binding constant of $\mathrm{K}_{l a}=3.0 \times 10^{6} \mathrm{M}^{-1}$ (Table 2 and ESI Tables S1 and S2). Comparing the ${ }^{1} \mathrm{H}-\mathrm{NMR}$ spectrum of $1 \mathrm{a}$ alone in $\mathrm{D}_{2} \mathrm{O}$ and the spectrum with 1 equivalent of $\mathrm{CB}[7]$ (1a $\subset \mathrm{CB}[7])$, diagnostic shifts for the ${ }^{1} \mathrm{H}-\mathrm{NMR}$ peaks belonging to 1a can be clearly highlighted (Figure 2). ${ }^{[36,37]}$ In the CB[7]-HIC geometry obtained, protons on $s p^{2}$ carbons exhibit a typical up-field shift, while aliphatic protons adjacent to the amine exhibit a down-field shift.

Table 1. Conversion of $1 \mathrm{a}-\mathrm{d}$ in the presence of $\mathrm{CB}[7]$ in aqueous solution. All reactions were performed at $37^{\circ} \mathrm{C}, 40-60 \mathrm{mM}$ in $\mathrm{D}_{2} \mathrm{O} .{ }^{a}$ Time taken for reactions to reach $50 \%$ completion. ${ }^{b}$ All reactions went to completion except entries 1 and 10, which were monitored for $25 \mathrm{~d}$ with low conversion ( $8 \%$ and $9 \%$, respectively).

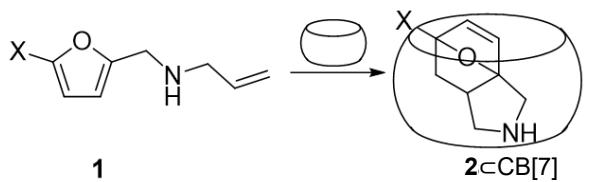

\begin{tabular}{ccccc}
\hline Entry & Compound & $\mathbf{X}$ & Equiv. of CB[7] & Time (h) $^{a}$ \\
1 & $\mathbf{1 a}$ & $\mathrm{H}$ & - & $600^{b}$ \\
2 & $\mathbf{1 a}$ & $\mathrm{H}$ & 1 & 1.2 \\
3 & $\mathbf{1 a}$ & $\mathrm{H}$ & 0.1 & 50 \\
4 & $\mathbf{1 b}$ & $\mathrm{Br}$ & - & 240 \\
5 & $\mathbf{1 b}$ & $\mathrm{Br}$ & 1 & 0.2 \\
6 & $\mathbf{1 b}$ & $\mathrm{Br}$ & 0.1 & 21 \\
7 & $\mathbf{1 c}$ & $\mathrm{Cl}$ & - & 288 \\
8 & $\mathbf{1 c}$ & $\mathrm{Cl}$ & 1 & 0.3 \\
9 & $\mathbf{1 c}$ & $\mathrm{Cl}$ & 0.1 & 15 \\
10 & $\mathbf{1 d}$ & $\mathrm{CH}_{3}$ & - & $600^{b}$ \\
11 & $\mathbf{1 d}$ & $\mathrm{CH}_{3}$ & 1 & 0.5 \\
12 & $\mathbf{1 d}$ & $\mathrm{CH}_{3}$ & 0.1 & 24 \\
\hline
\end{tabular}

The dienophile moiety plays an important role in the formation of such a unique 'two-in-one' complex with $\mathrm{CB}$ [7]. To demonstrate this, compound 1e (with the saturated tail $\mathrm{NCH}_{2} \mathrm{CH}_{2} \mathrm{CH}_{3}$, see Supplemetary Sections 1 and 2) was synthesized. Interestingly, if the dienophile is not present in the structure, the saturated alkyl side chain (propyl in this case, 1e Figure 1d) does not fold back inside the cavity as demonstrated by ${ }^{1} \mathrm{H}-\mathrm{NMR}$ of $1 \mathbf{e} \subset \mathrm{CB}[7]$ (ESI Section 2) and therefore does not form a CB[7]-HIC complex. In addition, the amount of change in enthalpy in the formation of the $1 \mathbf{e} \subset \mathrm{CB}$ [7] complex is lower when compared to the 1a-d $\subset \mathrm{CB}$ [7] complexes, indicating a smaller cavity space being occupied by $1 e$ (Table 2, and ESI Tables S1 and S2), suggesting that only the furan moiety is encapsulated. ${ }^{[37,38]}$ This experimental data highlights the possibility to obtain substrate selectivity of the HIC using CB[7](see ESI Table S3).

Theoretical calculations (PCM B3LYP-D3/6-31+G*) are in agreement with these experimental results. As depicted in the ESI Figure S12, an ion-dipole interaction is evident in the HIC complex between the protonated amine and the carbonyl portal while the double bond of the dienophile in the HIC geometry is parallel to the diene carbon-carbon bond and not to the carbon-oxygen bond of the furan. This arrangement was found to be both enthalpically and entropically favorable, giving rise to additional stabilization when compared to the saturated tail, analogue 1e, in solution without CB[7] (see ESI Table S3). The calculations therefore suggest that a $\pi-\pi$ interaction between the diene and the dienophile is a key requirement to form the reactive HIC within the $\mathrm{CB}[7]$ cavity.

The importance of the CB[7] stabilized HIC in yielding the desired Diels-Alder product is highlighted in Table 1. In accordance with previous reports in the literature, compound 1a does not undergo a cycloaddition reaction in an efficient manner in water (entry 1, Table $1,<10 \%$ after $25 \mathrm{~d}$ ). ${ }^{[33]}$ In the presence of $\mathrm{CB}$ [7] the Diels-Alder reaction for 19 reached $50 \%$ completion in $\sim 1 \mathrm{~h}$, and $>90 \%$ completion in $6 \mathrm{~h}$ (entries 1 and 2, Table 1).

To explore the scope of this reaction and the effect of substitution on reaction rates, the 5- $\mathrm{Br}(\mathbf{1 b}), 5-\mathrm{Cl}(\mathbf{1 c})$ and 5-methyl (1d) analogues, presented in the ESI Section 1, were synthesized in high yield. A similar CB[7]-HIC was observed, by ${ }^{1} \mathrm{H}$ NMR and ITC, for all substrates when treated with $\mathrm{CB}$ [7] (see ESI Sections 1 and 2). Furthermore, when a stoichiometric amount of $\mathrm{CB}$ [7] is introduced, the Diels-Alder reactions exhibit pseudo-first order kinetics and a substantial rate enhancement is measured for all substrates $\left(\mathrm{k}_{l b \subset C B[7]} / \mathrm{k}_{l b}\right.$ and $\mathrm{k}_{l c \subset C B[7]} / \mathrm{k}_{l c}>1000$, see ESI Section 2$)$. The halogen substituents induce a greater reaction rate compared to the methyl and unsubstituted homologues, requiring 


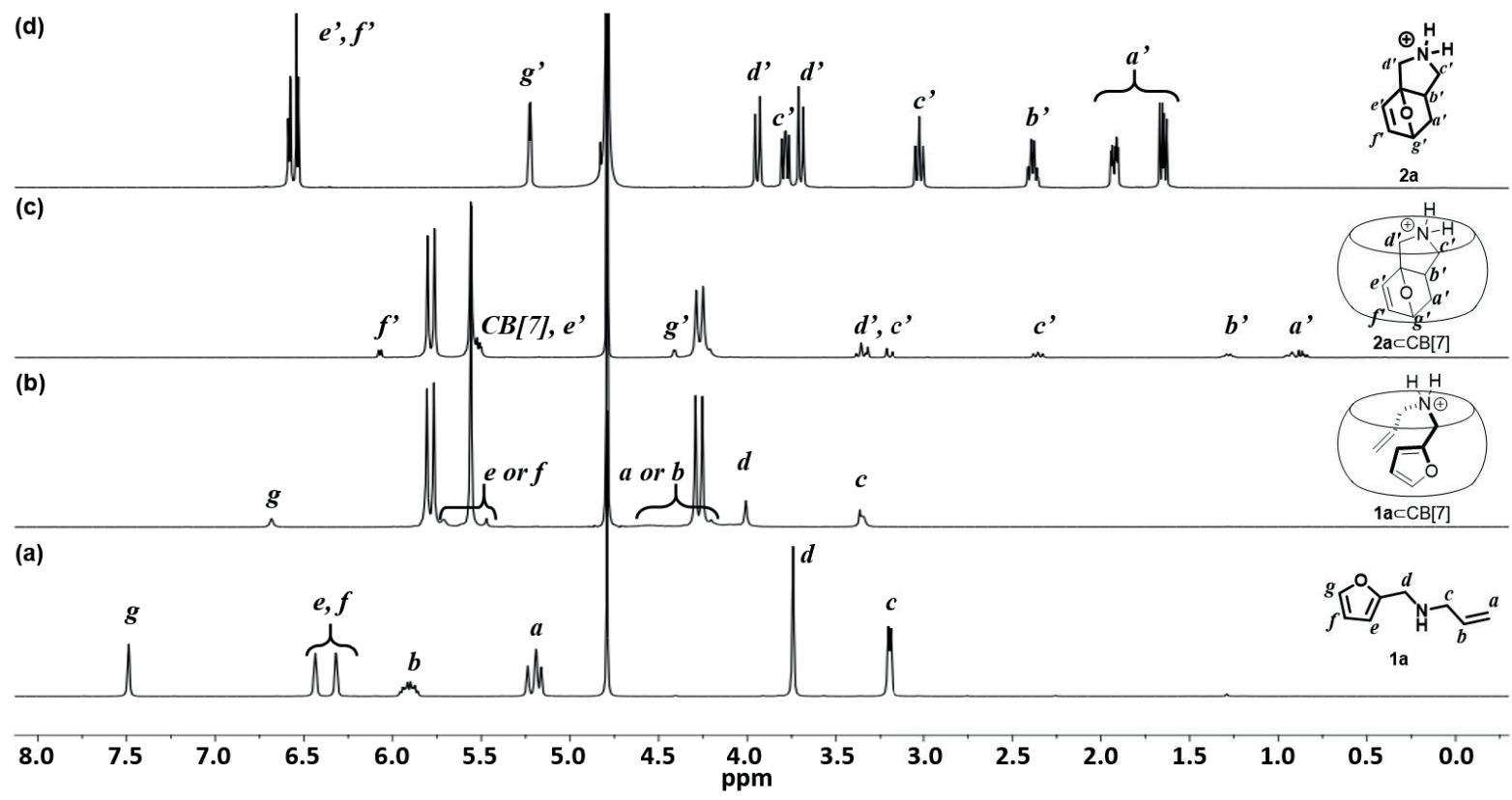

Figure 2. ${ }^{1} \mathbf{H}-N M R$ spectra of a) substrate 1a; b) substrate 1a encapsulated within $\mathrm{CB}[7]$ (1a $\subset$ CB[7]); c) cyclized product 2a, encapsulated within CB[7] $(\mathbf{2} \mathbf{a} \subset \mathrm{CB}[7])$; d) pure product $\mathbf{2} \mathbf{a}$ in $\mathrm{D}_{2} \mathrm{O}$.

Table 2. Thermodynamic data in sodium phosphate buffer $(10 \mathrm{mM}$, pH 7.0, 298K).

\begin{tabular}{ccccc}
\hline Compound & $\mathbf{K}\left(\mathbf{M}^{-1}\right)$ & $\Delta \mathbf{G}(\mathbf{k c a l} / \mathbf{m o l})$ & $\Delta \mathbf{H}(\mathbf{k c a l} / \mathbf{m o l})$ & $\mathbf{T} \Delta \mathbf{S}(\mathbf{k c a l} / \mathbf{m o l})$ \\
1a & $3.0 \times 10^{6}$ & $-8.8 \pm 0.1$ & $-8.2 \pm 0.1$ & $0.6 \pm 0.2$ \\
2a & $6.3 \times 10^{6}$ & $-9.3 \pm 0.2$ & $-7.1 \pm 0.1$ & $2.2 \pm 0.3$ \\
$\mathbf{1 b}$ & $1.0 \times 10^{6}$ & $-8.2 \pm 0.1$ & $-6.1 \pm 0.1$ & $2.1 \pm 0.2$ \\
2b & $2.9 \times 10^{6}$ & $-8.8 \pm 0.1$ & $-9.0 \pm 0.2$ & $-0.2 \pm 0.3$ \\
$\mathbf{1 c}$ & $4.6 \times 10^{5}$ & $-7.7 \pm 0.1$ & $-6.7 \pm 0.1$ & $1.0 \pm 0.2$ \\
2c & $6.3 \times 10^{6}$ & $-9.3 \pm 0.1$ & $-8.8 \pm 0.1$ & $0.5 \pm 0.2$ \\
$\mathbf{1 d}$ & $1.1 \times 10^{6}$ & $-8.2 \pm 0.1$ & $-5.9 \pm 0.1$ & $2.3 \pm 0.2$ \\
2d & $5.6 \times 10^{6}$ & $-9.2 \pm 0.2$ & $-7.9 \pm 0.2$ & $1.3 \pm 0.4$ \\
1e & $2.3 \times 10^{5}$ & $-7.3 \pm 0.1$ & $-3.4 \pm 0.1$ & $3.9 \pm 0.2$ \\
\hline
\end{tabular}

between $10-15 \mathrm{~min}$ for $\mathbf{1 b}-\mathbf{c}$ at $37{ }^{\circ} \mathrm{C}$ to reach $50 \%$ conversion (entries 5 and 8 , Table 1), in agreement with the known "halogen effect" for these systems. ${ }^{[39]}$ Comparatively, in the absence of CB[7], 288 and $244 \mathrm{~h}$ is required for $\mathbf{1 b}$ and $\mathbf{1 c}$ to reach $50 \%$ conversion, respectively.

To determine the potential of $\mathrm{CB}$ [7] to act at catalytic quantities, substrates 1a-d were treated with 0.1 equiv. of $\mathrm{CB}[7]$ in $\mathrm{D}_{2} \mathrm{O}$, yielding the desired uncomplexed products in solution (all stoichiometric and catalytic reactions were performed in aqueous solution as well as in PBS buffer at $\mathrm{pH} 7.0,37^{\circ} \mathrm{C}$, see ESI Section 2). Products $\mathbf{2 a - d}$ can be readily isolated from the crude mixture by simple solvent extraction with purity $>95 \%(\mathbf{1 a} \rightarrow \mathbf{2 a}, 75 \%$ isolated yield in $480 \mathrm{~h}, \mathbf{1 b} \rightarrow \mathbf{2 b}, 83 \%$ isolated yield in $96 \mathrm{~h}, \mathbf{1 c} \rightarrow \mathbf{2 c}, 78 \%$ isolated yield in $48 \mathrm{~h}, \mathbf{1 d} \rightarrow \mathbf{2 d}, 61 \%$ isolated yield in $216 \mathrm{~h}$; for the x-ray structures of compounds $\mathbf{2 c}$ and $\mathbf{2 d}$, see ESI). To the best of our knowledge this is the first method that allows for the preparation of these synthons in biomimetic and catalytic conditions, without the use of protecting or activating groups on the secondary amine. ${ }^{[31,34,35]}$
With the purpose of highlighting the pivotal role of $\mathrm{CB}$ [7], compound 1c was chosen as the substrate for a number of control experiments due to its fast reaction rate. Substrate 1c in $\mathrm{D}_{2} \mathrm{O}$ was exposed to 0.1 equiv. of $\mathrm{CB}$ [7] precomplexed with a strong binder such as adamantyl amine $\mathrm{HCl}$ salt $\left(\mathrm{K}=10^{12}-10^{14} \mathrm{M}^{-1} ; \mathrm{ADA} \subset \mathrm{CB}[7]\right),{ }^{[21]}$ as well as 0.1 equiv. of $\mathrm{CB}[6]$, a $\mathrm{CB}[n]$ homologue too small to accommodate the HIC conformation within its cavity. These reactions were monitored over $120 \mathrm{~h}$ using ${ }^{1} \mathrm{H}$ NMR (see ESI Section 2). The reactions of $1 \mathrm{c}$ in $\mathrm{D}_{2} \mathrm{O}, \mathbf{1 c}$ with 0.1 equiv. of $\mathrm{ADA} \subset \mathrm{CB}$ [7] and 1c with 0.1 equiv. of $\mathrm{CB}[6]$ all resulted in a similar yield for $\mathbf{2 c}$. These results are indicative of the fact that the formation of the HIC geometry in the CB[7] cavity is necessary to catalyze this transformation.

In order to investigate the mechanism associated with these catalytic transformations, ITC titrations of compounds 2a-d were performed (Table 2). It was found that the binding constant for the products was higher than the starting materials $(\mathbf{1 a}-\mathbf{d})$ in all cases $\left(\mathrm{K}_{2}>\mathrm{K}_{l}\right)$. These results are intriguing as, despite the higher thermodynamic stability of complexes 2a-d $\subset \mathrm{CB}$ [7] compared to $\mathbf{1 a}-\mathbf{d} \subset \mathrm{CB}$ [7], the reactions proceeded in good yield with only a catalytic amount (0.1 equiv.) of CB[7]. These systems are notably different from those previously reported in the literature where a lower binding affinity of the products formed with the cavity is observed, providing a driving force for catalytic turnover. ${ }^{[40,41]}$

$$
\frac{\partial \beta}{\partial t}=k_{D A} \cdot r \cdot \alpha
$$

Product inhibition is an inherent characteristic of DielsAlderases on account of the structural similarity between 

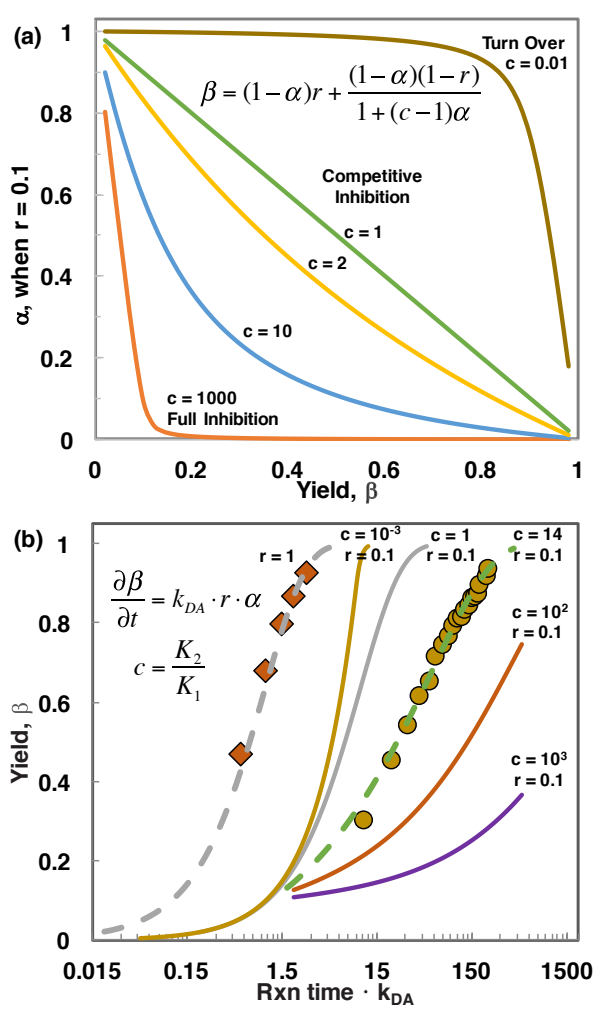

Figure 3. Effect of product inhibition illustrated by a) the relationship between $\alpha$, the ratio of $\mathrm{CB}[7]$ occupied by reactant, and $\beta$, the yield; and b) the (dimensionless) reaction progress under different $r$ values, the amount of $\mathrm{CB}[7]$ added, and $c$, the relative binding affinity.

starting materials and products. ${ }^{[2,3]}$ However, it is not clear to what extent product inhibition can be tolerated in a practical application. With this in mind, CB[7] offers a unique opportunity to understand how reaction rate is affected by the relative affinity $\left(c=K_{2} / K_{1}\right)$ between products and reactants in a host-guest catalytic system.

The conversion rate of the reaction, as shown in $\mathrm{Eq} \mathrm{1,} \mathrm{is}$ determined by the rate constant of $\mathrm{CB}$ [7]-HIC $\left(k_{D A}\right)$ as well as the number of active sites $(1 \subset \mathrm{CB}[7])$ in the system. The number of actives sites is further determined by $r$, defined as the equiv. of $\mathrm{CB}[7]$, and $\alpha$, the ratio of $\mathrm{CB}$ [7] occupied by reactants. As the exchange rate $\left(k_{e x}: 10^{-3}-10^{-2} s^{-1}\right)$ for equilibrating this system is faster than the reaction rate $\left(k_{D A}\right.$ : ca. $10^{-4} s^{-1}$, see ESI Section 5), an instantaneous equilibrium at any time of the reaction can be assumed. This aided in the formulation of a relationship between $\alpha, \beta$ (reaction yield), and $c$, the relative affinity (see the ESI Section 5 for full derivation).

Figure $3 \mathrm{a}$ illustrates a simulation of the number of available active sites (reflected by $\alpha$ ) depending on the reaction yield $(\beta)$ upon addition of 0.1 equiv. of $\mathrm{CB}$ [7] $(r=0.1)$. It shows that a typical catalytic turnover (brown trace, Figure $3 \mathrm{a}$ ) or full product inhibition (orange trace, Figure 3a) requires the binding constant of the starting material be either larger or smaller, respectively, than the resulting product by $>2-3$ orders of magnitude. Both of these scenarios are rarely observed for Diels-Alderases. ${ }^{[2,3]}$ Rather, compet- itive product inhibition is a more suitable description for the observation of $\mathrm{CB}$ [7]-HIC catalysis, where the relative binding affinity ranges from $1-10$ (Table 2). On account of product inhibition, the number of available active sites typically decreases as the reaction proceeds $(\beta)$. However, under competitive inhibition (green, yellow, blue traces, Figure 3a) the decrease is much slower compared to the full inhibition regime (orange trace, Figure 3a). Therefore, starting material will always occupy an appropriate amount of $\mathrm{CB}$ [7] cavities to allow the reaction to proceed, leading to reasonable catalytic half-lives.

The experimentally obtained $k_{D A}$ from the stoichiometric reactions can be used to simulate the reaction process for the catalytic experiments. As illustrated in Figure 3b, for $r=0.1$, a reaction where turnover readily occurs $(c=0.001)$, approaches full conversion promptly; conversely, a reaction where full product inhibition takes place $(c=100$ or 1000) cannot reach completion within a practical period of time. The data obtained from the reaction of $1 \mathrm{a}$ with 0.1 equiv. of $\mathrm{CB}$ [7] (Table 1, Entry 3) could be readily fitted with a $c$ value of 14. This result shows that although binding affinity of products is around 10 times larger than the starting materials, full conversion can be approached within a short reaction time. It is worth noting that all catalytic reactions (i.e. $r=0.1$ ), even in the 'Turn over' regime, are slower than the stoichiometric reaction $(r=1)$, which suggests that any increase in the reaction time for catalytic reactions observed in this work is only partially due to product inhibition, but mainly arises from the decrease in the amount of catalyst by 10 times (from 1 to 0.1 equiv.).

Our study demonstrates that even in the presence of competitive product inhibition, the desired product can be isolated in high yield overcoming any potential practical issues. Moreover, competitive product inhibition can be controlled by adjusting either the rate constant $\left(k_{D A}\right)$ or the amount of catalyst $(r)$. In particular, we demonstrate that for our system, the rate constants $\left(k_{D A}\right)$ for these reactions are significantly enhanced upon formation of the CB[7]-HIC geometry, which is associated with a highly reactive conformation for the substrates. The comparable values for the binding constants of the starting materials and products still enables catalytic amounts of $\mathrm{CB}$ [7] $(r=0.1)$ to be used, resulting in short reaction times and facilitating product isolation. The in-depth understanding obtained here could be applied to general Diels-Alderase catalysis and other enzymes that suffer from potential product inhibition. ${ }^{[2]}$

In conclusion, we have demonstrated that $\mathrm{CB}[7]$ is able to catalyze Diels-Alder reactions for substituted and previously unreactive $\mathrm{N}$-allyl-2-furfurylamines, imitating the role of a Diels-Alderase enzyme. This is possible as CB[7] is able to induce a reactive conformation in the substrate. Despite the reaction products exhibiting higher binding affinities for $\mathrm{CB}$ [7] than their reactants, we have shown that Diels-Alder reactions can indeed proceed under mild and biomimetic catalytic conditions. On account of competitive binding between $\mathrm{CB}[7]$ and both the starting material and product in 

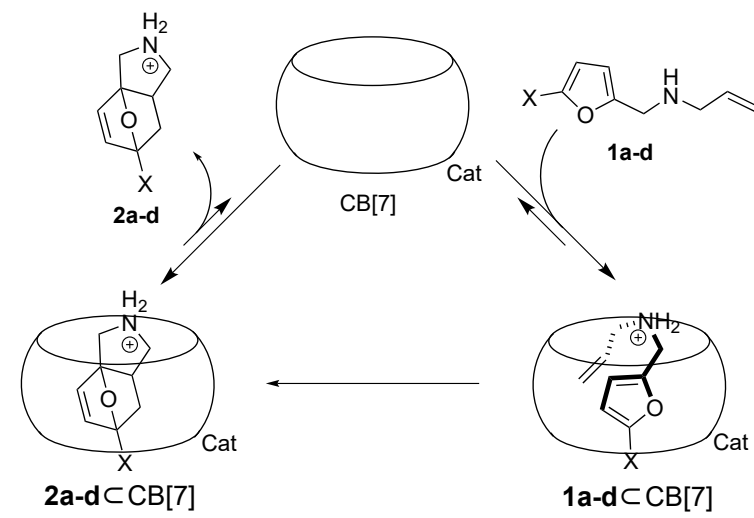

1a-d $\subset \mathrm{CB}[7]$

Figure 4. Proposed catalytic cycle.

solution $(\mathbf{1} \subset \mathrm{CB}[7]$ and $\mathbf{2} \subset \mathrm{CB}[7])$, even in the presence of a catalytic amount of $\mathrm{CB}$ [7] (Figure 4) the reaction rate was significantly enhanced (half life $<2 \mathrm{~d}$ ). This work highlights that $\mathrm{CB}[n]$ host-guest chemistry cannot only be utilized to access novel compounds through green catalytic routes, but contributes to the understanding of how enzymes could catalyze Diels-Alder reactions despite potential product inhibition.

\section{References}

[1] C. D. Fage, E. A. Isiorho, Y. Liu, D. T. Wagner, H.-w. Liu, A. T Keatinge-Clay, Nat. Chem. Biol. 2015, 11, 256-258.

[2] K. Klas, S. Tsukamoto, D. H. Sherman, R. M. Williams, J. Org. Chem. 2015, 80, 11672-11685.

[3] T. Ose, K. Watanabe, T. Mie, M. Honma, H. Watanabe, M. Yao, H. Oikawa, I. Tanaka, Nature 2003, 422, 185-189.

[4] J. Jiang, Y. Meng, L. Zhang, M. Liu, J. Am. Chem. Soc. 2016, 138, 15629-15635.

[5] Q.-Q. Wang, N. Luo, X.-D. Wang, Y.-F. Ao, Y.-F. Chen, J.-M. Liu, C.-Y. Su, D.-X. Wang, M.-X. Wang, J. Am. Chem. Soc. 2017, 139, 635-638.

[6] Q. Zhang, L. Catti, V. R. I. Kaila, K. Tiefenbacher, Chem. Sci. 2017, $8,1653-1657$

[7] D. Zhang, A. Martinez, J.-P. Dutasta, Chem. Rev. 2017, 117, 49004942.

[8] A. Desmarchelier, X. Caumes, M. Raynal, A. Vidal-Ferran, P. W. van Leeuwen, L. Bouteiller, J. Am. Chem. Soc. 2016, 138, 49084916.

[9] M. Raynal, P. Ballester, A. Vidal-Ferran, P. W. van Leeuwen, Chem. Soc. Rev. 2014, 43, 1734-1787.

[10] A. J. Boersma, R. P. Megens, B. L. Feringa, G. Roelfes, Chem. Soc. Rev. 2010, 39, 2083-2092.

[11] F. Biedermann, D. Hathazi, W. M. Nau, Chem. Commun. 2015, 51, 4977-4980.

[12] Y.-H. Wang, H. Cong, F.-F. Zhao, S.-F. Xue, Z. Tao, Q.-J. Zhu, G. Wei, Catal. Commun. 2011, 12, 1127-1130.
[13] K. Reddy, T. Cavallini, G. Demets, L. Silva, New J. Chem. 2014, 38 , 2262-2264.

[14] C. Klöck, R. N. Dsouza, W. M. Nau, Org. Lett. 2009, 11, 2595-2598.

[15] N. Basilio, L. García-Río, J. A. Moreira, M. Pessêgo, J. Org. Chem. 2010, 75, 848-855.

[16] S. Y. Jon, Y. H. Ko, S. H. Park, H.-J. Kim, K. Kim, Chem. Commun. 2001, 1938-1939.

[17] R. Wang, L. Yuan, D. H. Macartney, J. Org. Chem. 2006, 71, 12371239.

[18] S. M. de Lima, J. A. Gómez, V. P. Barros, G. d. S. Vertuan, M. das Dores Assis, C. F. de Oliveira Graeff, G. J.-F. Demets, Polyhedron 2010, 29, 3008-3013.

[19] X. Lu, E. Masson, Org. Lett. 2010, 12, 2310-2313.

[20] L. Zheng, S. Sonzini, M. Ambarwati, E. Rosta, O. A. Scherman, A. Herrmann, Angew. Chem. Int. Ed. 2015, 54, 13007-13011.

[21] S. J. Barrow, S. Kasera, M. J. Rowland, J. del Barrio, O. A. Scherman, Chem. Rev. 2015, 115, 12320-12406.

[22] C. Yang, T. Mori, Y. Origane, Y. H. Ko, N. Selvapalam, K. Kim, Y. Inoue, J. Am. Chem. Soc. 2008, 130, 8574-8575.

[23] B. Chen, S.-F. Cheng, G.-H. Liao, X.-W. Li, L.-P. Zhang, C.-H. Tung, L.-Z. Wu, Photochem. Photobiol. Sci. 2011, 10, 1441-1444.

[24] S. Y. Jon, Y. H. Ko, S. H. Park, H. J. Kim, K. Kim, Chem. Commun. 2001, 1938-1939.

[25] C. O. Kappe, S. S. Murphree, A. Padwa, Tetrahedron 1997, 53, 14179-14233.

[26] M. Ikoma, M. Oikawa, M. Sasaki, Tetrahedron 2008, 64, 27402749.

[27] O. Arjona, A. G. Csákÿ, M. C. Murcia, J. Plumet, Tetrahedron Lett. 2000, 41, 9777-9779.

[28] O. Arjona, A. G. Csákÿ, M. C. Murcia, J. Plumet, J. Org. Chem. 1999, 64, 7338-7341.

[29] B. M. Novak, R. H. Grubbs, J. Am. Chem. Soc. 1988, 110, 960-961.

[30] B. M. Novak, R. H. Grubbs, J. Am. Chem. Soc. 1988, 110, 75427543.

[31] C. Andrés, G. Maestro, J. Nieto, R. Pedrosa, S. García-Granda, E. Pérez-Carreño, Tetrahedron Lett. 1997, 38, 1463-1466.

[32] C. Andrés, M. García-Valverde, J. Nieto, R. Pedrosa, J. Org. Chem. 1999, 64, 5230-5236.

[33] P. Sammes et al., J. Chem. Soc. Perkin Trans. 1 1998, 2017-2022.

[34] P. Sammes et al., Chem. Commun. 1997, 513-514.

[35] H. W. Gschwend, M. J. Hillman, B. Kisis, R. K. Rodebaugh, J. Org. Chem. 1976, 41, 104-110.

[36] W. L. Mock, N. Y. Shih, J. Org. Chem. 1986, 51, 4440-4446.

[37] Z. Huang, K. Qin, G. Deng, G. Wu, Y. Bai, J. Xu, Z. Wang, Z. Yu, O. A. Scherman, X. Zhang, Langmuir 2016.

[38] F. Biedermann, V. D. Uzunova, O. A. Scherman, W. M. Nau, A. De Simone, J. Am. Chem. Soc. 2012, 134, 15318-15323.

[39] S. N. Pieniazek, K. N. Houk, Angew. Chem. Int. Ed. 2006, 45, 14421445.

[40] M. Yoshizawa, M. Tamura, M. Fujita, Science 2006, 312, 251 -254.

[41] J. Kang, J. Rebek, Nature 1997, 385, 50-52. 